\title{
Best videos of the year for the International Brazilian Journal of Urology 2014
}

\section{Dear readers,}

The past year has been another memorable one for our journal and particularly for the video section. We gave expanded our editorial board of the video section to include international leaders in all facets of our specialty insuring that the quality of our reviews are kept to the highest standards while enabling these leaders to share their viewpoints and insight through their editorial comments accompanying accepted video abstracts. In addition over the past 6 months, we have transitioned the video section to an electronic video submission and review format enabling video submissions to be processed in a very expeditious manner while serving a state-of-the art platform for our journal and video section for the many years to come. In this editorial letter, I would like to honor as has been done in recent years, our accepted videos that were selected as the best of the year by our editorial board. In making their selection, the video section editorial board members could not select a video they served as a co-author on. In this regard, editorial board members were sent the weblinks to access all accepted videos and abstracts subsequent to which they were asked to review all videos and rank them thereafter from highest to lowest ranked accepted video which were then cumulated in making our selection as the best videos of the year. The 1st prize for best video of the year was by the group of Dr. Rafael Rebouças et al. (1). from the faculty of Medical Sciences of Paraiba and Department of Urology from the Police Military Hospital Edson Ramalho, Brazil and is titled "Pure laparoscopic augmentation ileocystoplasty". In this beautiful depiction by Dr. Rebouças and colleagues, the authors employ a four port transperitoneal technique in performing an augmentation ileocystoplasty in a 15 year old female with voiding dysfunction and a prior history of Guillain-Barre syndrome. The great merit of this video is that minimally invasive surgery (MIS) can be adopted to such complex reconstructive techniques whereby further expanding the widespread applications of MIS in all avenues of our specialty. The 2nd prize is awarded to the video by Jared Wallen et al. (2) from the University of South Florida and Moffitt Cancer Center entitled "Optimizing penile length in patients undergoing partial penectomy for penile cancer: Novel application of the ventral phalloplasty oncoplastic technique". This video originated from my group employing a surgical reconstruction technique first described by Dr. Rafael Carrion and adapting it to increase functional penile length in patients with penile cancer undergoing primary neoplasm resection. Clearly, the loss of sexual function following partial penectomy in the majority of patients pertains to the loss of penile length which can in consequence can adversely impact quality of life hence this surgical approach offers great promise in minimizing this impact on patients while not 


\section{EDITOR'S}

dramatically increasing the complexity of the surgery. Notably this year, we had a number of videos (in excess of 5) selected for the 3rd prize making it impossible to select one of these as superior to the others.

I want to take this opportunity to thank our entire editorial staff, authors who have submitted such high quality submissions to our section, and lastly but most importantly all of our readers for supporting our video section. You truly make the International Brazilian Journal of Urology and the video section such a great success and we look forward to further significant growth and international recognition with your assistance in the months to years to come.

\section{REFERENCES}

1. Rebouças RB, Monteiro RC, Souza TN, Aragão AJ, Burity CR, Nóbrega JC, Oliveira NS, Abrantes RB, Dantas Júnior LB, Cartaxo Filho R, Negromonte GR, Sampaio Rda C, Britto CA. Pure laparoscopic augmentation ileocystoplasty. Int Braz J Urol. 2014;40:858-9.

2. Wallen JJ, Baumgarten AS, Kim T, Hakky TS, Carrion RE, Spiess PE. Optimizing penile length in patients undergoing partial penectomy for penile cancer: novel application of the ventral phalloplasty oncoplastic technique. Int Braz J Urol. 2014;40:708-9.

\section{Philippe E. Spiess, MD}

Associate Member, Department of GU Oncology

Moffitt Cancer Center, Tampa, FL, USA

Video Section Editor, International Brazilian Journal of Urology

E-mail: philippe.spiess@moffitt.org 